\title{
Perubahan Kadar Saturasi Oksigen pada Pasien Dewasa yang Dilakukan Tindakan Suction Endotrakeal Tube di Ruang ICU RSUD Ulin Banjarmasin
}

\author{
Hammad $^{1(\mathrm{CA})}$, M. Ichwan Rijani ${ }^{2}$, Marwansyah $^{3}$ \\ ${ }^{1(\mathrm{CA})}$ Poltekkes Kemenkes Banjarmasin Indonesia; hammad.martapura@ gmail.com (Corresponding \\ Author) \\ ${ }^{2}$ Poltekkes Kemenkes Banjarmasin Indonesia \\ ${ }^{3}$ Poltekkes Kemenkes Banjarmasin Indonesia
}

\begin{abstract}
Dealing with for aviation route impediment because of extreme gathering of discharges should be possible with pull, attractions is finished by embeddings pull catheter tube into endotracheal cylinder or tracheostomy which plans to free aviation route. Endotracheal pull in fundamentally sick patients can cause expanded intracranial weight, mind growing and foundational hypoxemia may even prompt demise. The simplest method to discover hypoxemia is by taking a gander at the patient's oxygen immersion of fringe oxygen immersion is an introduction of hemoglobin ties with oxygen in the courses with typical qualities between $95-100 \%$. This examination expects to investigate changes in oxygen immersion levels of patients previously, during and after the pull endotracheal tube acted in Intensive Care Unit Ulin Banjarmasin Hospital. This examination strategy is quantitative with similar plan. The populace in this exploration are largely patients who had endotracheal cylinder and attractions was done, the example in the examination are 25 respondents with Probability inspecting strategy, investigated by combined $\mathrm{T}$ test. The aftereffects of this examination at the hour of 1 "- 3" normal oxygen immersion change of $0-1 \%$, while $4 "-6$ " on normal by $2-3 \%$ and at 7 "- 10 " on normal by $2-5 \%$. Matched T-test results appeared there was an adjustment in oxygen immersion level in grown-up patients performed endotracheal tube attractions in Intensive Care Unit Ulin Banjarmasin Hospital
\end{abstract}

Keywords: Suction, Endotracheal tube, Saturation Oxygen

\begin{abstract}
ABSTRAK
Penanganan untuk obstruksi jalan nafas oleh mengumpulkan sekret yg berlebih bisa dilakukan menggunakan tindakan suction, suction dilakukan menggunakan cara memasukkan selang kateter melalui tabung endotrakeal atau trakeostomi yg mengharapkan buatmembebaskan jalan nafas. Tindakan hisap endotrakealpada pasien kritis bisa terus Peningkatan tekanan intrakranial, pembengkakan otak dan hipoksemia sistemik bahkan bisa teruskematian. Cara termudahbuat Tahu hipoksemia adalah menggunakan cara melihat saturasi oksigen perifer pasien, saturasi oksigen adalah presentasi hemoglobin yang berikatan dengan oksigen pada arteri menggunakannilai normal antara 95-100\%. Penelitian inibuat menganalisa kadar saturasi oksigen sebelum, waktu juga setelah dilakukan tindakan suction endotracheal tube diICU RSUD Ulin Banjarmasin. Metode penelitian iniadalah kuantitatif dengandesain komparatif. Populasipada penelitian ini semua pasien yang terpasang tabung endotrakeal dan dilakukan hisap, sampel dalam penelitian sebesar 25 orang dengan teknik Probability sampling, dianalisis dengan uji $\mathrm{T}$ berpasangan. hasil penelitian di waktu 1 "-tiga" rata-rata perubahan saturasi oksigen sebesar 0-1\%, kompilasi 4 "- 6" rata-homogen sebesar 2-3\% juga saat 7 "-10" homogen-rata sebesar doa-5\%. hasil uji T berpasangan mengambarkan berada perubahan kadar saturasi oksigen pada pasien dewasa yang dilakukan tindakan sot endotrakeal tube di ICU RSUD Ulin Banjarmasin.
\end{abstract}

Kata Kunci : Suction, Endotracheal tube, Saturasi Oksigen 


\section{PENDAHULUAN}

Penanganan buat obstruksi jalan napas dampak akumulasi sekret yang berlebihan dapat dilakukan dengan tindakan penghisapan lendir (suction) dengan memasukkan selang kateter suction melalui hidung, mulut, endotrakeal tube juga trakeostomi yg bertujuan buat membebaskan jalan napas, mengurangi retensi sputum dan mencegah infeksi paru. Secara umum pasien yang mengalami obstruksi jalan napas mempunyai respon tubuh yang kurang baik buat mengeluarkan benda asing, sehingga sangat dibutuhkan tindakan penghisapan lendir atau (suction) (Nurachmah \& Sudarsono, 2000 dalam Irmawan \& Muflihatin, 2017).

Endotrakeal suction dapat didefinisikan menjadi komponen terapi hygiene bronkial yg melibatkan aspirasi mekanis sekresi paru yg dilakukan perawat untuk menerima oksigenasi yang efektif (Elsaman, 2017). Tindakan suction endotrakeal di pasien kritis bisa mengakibatkan terjadinya penurunan kadar saturasi oksigen arteri yang membuahkan di peningkatan intrakranial pressure, pembengkakan otak serta hipoksemia sistemik bahkan dapat mengakibatkan kematian (Idjradinata \& Eli Kosasih, 2013).

Pengaruh sampingan dari suction menurut penelitian Manggorie (2013) diantaranya dapat mengakibatkan, penurunan saturasi oksigen berkurang sampai 5\%, mengakibatkan perdarahan, peningkatan tekanan darah sistolik hingga $200 \mathrm{mmHg}$, penurunan tekanan darah diastolik hingga 80 mmHg. dari Elsaman, (2017) komplikasi atau dampak berasal suction endotrakeal merupakan mirip kerusakan trakea, pendarahan, infeksi, gangguan kardiovaskular serta gangguan hemodinamik, gangguan pertukaran gas darah serta hipoksemia, bronkokonstriksi, atelektasis serta tekanan intrakranial meningkat. Hipoksia sendiri ialah suatu mekanisme utama yg terjadi di penyakit paru-paru akibat adanya penurunan suplai oksigen sebagai akibatnya tubuh kekurangan oksigen pada jaringan, sedangkan hipoksemia adalah kekurangan oksigen pada darah (Somantri, 2012). Hipoksemia terjadi saat kadar oksigen dalam darah turun, tekanan oksigen kurang berasal $60 \mathrm{mmHg}$ serta kadar saturasi hemoglobin kurang dari $90 \%$ (Semedi dan Hardiono,2012). Hipoksemia akan mengakibatkan terjadinya gagal nafas Jika PaO2 kurang asal $50 \mathrm{mmHg}$ dengan $\mathrm{PaCO} 2$ normal atau lebih rendah (Price \& Wilson, 2006).

Rumah Sakit Umum Daerah Ulin Banjarmasin merupakan sebuah rumah sakit rujukan dari rumah sakit daerah yang ada di Kalimantan Selatan dan Kalimantan Tengah. Berdasarkan data pasien ruang ICU RSUD Ulin Banjarmasin bulan Maret sampai dengan Agustus 2016, jumlah pasien di ICU sebanyak 624 orang, dan sekitar $40 \%$ dari jumlah pasien tersebut terpasang pipa endotrakeal, untuk mempertahankan jalan nafas pasien perawat melakukan tindakan penghisapan lendir atau suction.

Marton, et.al (2013) menngungkapkan bahwa tindakan suction adalah suatu tindakan keperawatan yang dilakukan kepada pasien yang tidak bisa dikeluarkan sekret atau lendir secara mandiri menggunakan menggunakan inderapenghisap. Pengisapanmerupakan prosedur wah pada ruang perawatan intensif pada pasien yang tabung endotrakeal terpasang atau trakeostomi. pada ruang intensif sebagian pasien memiliki konflik di pernafasan yang meminta donasi ventilator mekanik juga pemasangan pipa endotrakeal, dimana pemasangan ETT masuk sampai percabangan bronkus di saluran nafas.

Riset awal oleh peneliti RSUD Ulin Banjarmasin dari 10 penyebab kematian yang sering terjadi di ruang ICU gagal nafas menempati peringkat nomor 1 penyebab kematian terbesar pada tahun 2017 dengan angka kejadian 134 kasus dan selama 3 bulan terakhir (Oktober, November dan Desember) pada 
tahun 2017 didapatkan bahwa pasien yang terpasang endotrakeal intubasi (ETT) berjumlah \pm 58 orang.Setiap pasien yang terpasang endotrakeal intubasi atau ETT dilakukan suction dalam sehari paling sedikit $\pm 3-4 \mathrm{x} / \mathrm{sehari}$ oleh perawat ruangan. Mengingat tindakan suction endotrakeal sangat sering dan penting dilakukan pada pasien yang mengalami penumpukan sekret dan sangat berbahaya bagi pasien gagal nafas jika tidak dilakukan sesuai prosedur, karena dapat menyebabkan hipoksemia dan juga kematian jika tidak ditangani secara benar. Permasalahan ini memberikan inspirasi bagi peneliti menggali lebih jauh "analisis dinamika kadar saturasi oksigen pada pasien dewasa dengan diberi tindakan suction endotracheal tube diruang ICU RSUD Ulin Banjarmasin”.

\section{METODE}

Penelitian ini bersifat kuantitatif dengan jenis penelitian komparatif yaitu suatu rancangan penelitian yang digunakan buat mengkaji perbandingan terhadap impact pada grup subjek tanpa adanya suatu perlakuan berasal peneliti (Nursalam, 2015). Populasi pada penelitian ini ialah semua pasien dewasa yg terpasang endotrakeal tube serta dilakukan tindakan suction endotracheal tube di ruang ICU RSUD Ulin Banjarmasin. Sampel berjumlah 25 responden yang diambil dengan cara Simple Random sampling. Data dikumpulkan menggunakan instrumen lembar observasi yang diisi sebelum dan sesudah pasien mendapat tindakan suction endotrakeal tube di ruang ICU RSUD Ulin Banjarmasin. Analisa data yaitu analisis univariat dan analisa bivariat menggunakan uji Paired Sample T Test.

\section{HASIL}

1. Karakteristik responden

Tabel 1. Karakteristik Responden di Ruang ICU RSUD Ulin Banjarmasin $(n=25)$

\begin{tabular}{|c|c|c|c|}
\hline No & Karakteristik & Frekwensi & $\%$ \\
\hline \multirow[t]{4}{*}{1.} & Golongan Umur : & & \\
\hline & - 36-45 tahun & 5 & 20 \\
\hline & - $\quad 46-55$ tahun & 11 & 44 \\
\hline & - 56-65 tahun & 9 & 36 \\
\hline \multirow[t]{3}{*}{2.} & Jenis Kelamin & & \\
\hline & - Laki-Laki & 8 & 32 \\
\hline & - Perempuan & 17 & 68 \\
\hline \multirow[t]{3}{*}{3.} & Nilai Hemoglobin & & \\
\hline & - $\quad$ Normal (pria 13-18 g/dl;wanita 12-16 g/dl) & 16 & 64 \\
\hline & - Tidak Normal & 9 & 36 \\
\hline \multirow[t]{11}{*}{4.} & Diagnosa Medis & & \\
\hline & - Post Operasi Craniotomy & 8 & 32 \\
\hline & - $\quad$ Post Operasi Carpal Tunnel Release (CTR) & 2 & 8 \\
\hline & - Post Operasi Bypass Jejenum & 1 & 4 \\
\hline & - Post Operasi Vp. Shunt & 2 & 8 \\
\hline & - $\quad$ Acute Respiratory Distress Syndrome (ARDS) & 2 & 8 \\
\hline & - Cedera Kepala Berat (CKB) & 3 & 12 \\
\hline & - Gagal Nafas & 4 & 16 \\
\hline & - Tetanus & 1 & 4 \\
\hline & - Dyspneu & 1 & 4 \\
\hline & - Cardiac Arrest & 1 & 4 \\
\hline
\end{tabular}


Tabel 1 diatas menunjukkan bahwa paling banyak responden berusia 46-55 tahun (44\%), berjenis kelamin perempuan (68\%), nilai hemoglobin normal (64\%) serta diagnosa medis Post Operasi Craniotomy $(32 \%)$

2. Analisis Perubahan Kadar Saturasi Oksigen

Tabel 2. Analisis Perubahan Kadar SaO2 Klien Dewasa yang diberi Suction Endotrakeal Tube Di Ruang ICU RSUD Ulin Banjarmasin

\begin{tabular}{ccccc}
\hline No & \multicolumn{1}{c}{ Karakteristik } & Frekwensi & \% & Kategori \\
\hline 1. & $1-3$ menit saat tindakan & & & \\
& $-0-1 \%$ & 17 & 68 & Normal $(<5 \%)$ \\
& $-2-3 \%$ & 8 & 32 & Normal (<5\%) \\
\hline 2. & $4-6$ menit saat tindakan & & & \\
& $-0-1 \%$ & 3 & 12 & Normal $(<5 \%)$ \\
& $-2-3 \%$ & 22 & 88 & Normal (<5\%) \\
\hline 3. & $7-10$ menit saat tindakan & & & Normal $(<5 \%)$ \\
& $-0-1 \%$ & 0 & 0 & Normal $(<5 \%)$ \\
& $-2-3 \%$ & 16 & 64 & Normal $(<5 \%)$ \\
\hline 4. & $-4-7 \%$ & 9 & 36 & Normal $(<5 \%)$ \\
& $-0-1 \%$ & 9 & 36 & Normal $(<5 \%)$ \\
\hline
\end{tabular}

Berdasarkan tabel 2 perubahan saturasi oksigen saat tindakan suction endotrakeal tube pada menit 1 - 3 rata-rata $0-1 \%$ dengan frekuensi 17 responden (68\%), kemudian pada menit $4-6$ rata-rata $2-3 \%$ dengan frekwensi 22 responden (88\%) dan pada menit ke 7 - 10 saat tindakan rata-rata 2 - 3\% dengan frekwensi 16 responden (64\%). Kemudian hasil pengukuran pada menit ke 25 setelah tindakan suction endotrakeal tube rata-rata perubahan saturasi oksigen 2 - 3\% dengan frekwensi 16 responden (64\%).

\section{Analisis Multivariat}

Sebelum dilakukan analisis uji $\mathrm{T}$ sampel berpasangan atau berpasangan-uji sampel $\mathrm{T}$, dilakukan uji normalitas terlebih dahulu. Sesuai hasil uji normalitas pakai Kolmogorov-Smirnov memberikan nilai signifikansi sebanyak 0,152, adalah nilai signifikansi lebih akbar dari 0,05, maka bisadata statistik saturasi oksigen berdistribusi normal. Nilai t hitungdi uji tadi sebesar 0,05, sedangkan nilai t tabel sebanyak 2, 063. Nilai Nilai Pdi olehuji T sampel berpasangan yaitu 0,000. Jadibisa disimpulkan Jika nilai t hitung <t tabel $(-9,532<20,063)$ dan Nilai $\mathrm{P}(0,000<0,05)$, artinya ada disparitas kadar saturasi oksigen pada pasien dewasa yang dilakukan tindakan sot endotrakeal tube di ruang ICU RSUD Ulin Banjarmasin.

\section{PEMBAHASAN}

Berdasarkan tabel 2 hasil saturasi oksigen saat dilakukan tindakan suction endotrakeal tube detik 1"-3" dari 25 responden didapatkan 17 pasien (68\%) rata-rata perubahan hasil saturasi oksigennya berkisar dari (0-1\%), yang artinya dari 25 responden yang dilakukan tindakan suction endotrakeal tube dari 17 pasien ada yang mengalami perubahan (dalam kategori normal) dan ada yang tanpa perubahan. 
Kondisi ini ditemukan dikarenakan sebelum dilakukan tindakan suction 25 pasien tersebut diberikan tindakan hiperoksigenasi sebelum dilakukan proses suctioning. Hiperoksigenasi sendiri adalah tindakan yang diberikan sebelum melakukan tindakan suction dengan cara meningkatkan aliran oksigen, biasanya sampai $100 \%$ dengan menggunakan ventilator mekanik atau dengan kantong resusitasi manual (Kozier \& Erb, 2002).

Masih berdasarkan tabel 2 hasil pengukuran saturasi oksigen saat dilakukan tindakan suction endotrakeal tube terutama saat detik 4"-6" dari 25 responden didapatkan 22 pasien (88\%) mengalami penurunan saturasi oksigen rata-rata (2-3\%). Pada penelitian ini dari 25 sampel, sampel terbanyak berdasarkan jenis kelamin adalah perempuan 17 responden (68\%) dan laki-laki 8 responden (32\%). Martin et al, (2011) mengungkapkan ditemukannya kondisi gagal nafas pada wanita di atas laki-laki, disebabkan kapasitas compliance paru-paru pria lebih besar. Sedangkan jika berdasarkan usia, usia 46-55 tahun lebih banyak dengan 11 responden (44\%) dan berdasarkan usia rata-rata perubahan saturasi oksigen pasien pada usia 46-55 tahun berkisar antara (2-3\%). Menurut peneliti usia bisa menghipnotis perubahan kadar saturasi oksigen pasien alasan Jika semakin tua usia seorang elastisitas paru akan berkurang sebagai akibatnya bisa menghipnotis jumlah oksigen yg bisa ditampung paru-paru yang akhirnya menyadari di penurunan kadar oksigen pasien. menurut Hidayat, A. Azis, (2012) proses penuaan bisa terus perubahan pada fungsi pernapasan normal, seperti Penurunan elastisitas paru, pelebaran alveolus, dilatasi saluran bronkus juga kifosis tulang belakang yg istirahat melampaui paru jadi sungguh di penurunan kadar oksigen.

Selanjutnya saturasi oksigen pasien pada detik 7"-10" rata-rata mengalami perubahan sebesar (2$3 \%$ ) dengan 16 responden (64\%), dan (4-7\%) dengan 9 responden (36\%). Dari 9 responden yang mengalami perubahan kadar saturasi oksigen sebesar (4-7\%), 9 diantaranya memiliki kadar hemoglobin kurang dari normal artinya hemoglobin dapat mempengaruhi perubahan saturasi oksigen, sedangkan 16 responden yang lain bisa dipengaruhi oleh faktor yang lain seperti sirkulasi pada ekstremitas tidak lancar terutama pada bagian jari jika mengalami sianosis atau pasien bergerak-gerak saat dilakukan pengukuran. Fakta ini menurut Kozier \& Erb, (2016) faktor-faktor yang mempengaruhi bacaan saturasi oksigen ada 4 yaitu : hemoglobin, sirkulasi, aktivitas dan keracunan monoksida.

Sesuai hasil analisis menggunakan sampel $\mathrm{T}$ berpasangan atau berpasangan - sampel $\mathrm{T}$ test di pasien yang dilakukan tindakan sedot tabung endotrakeal sebelum juga setelah (25 ") di ruang ICU RSUD Ulin Banjarmasin mengambarkan ada perbedaan kadar saturasi oksigen di pasien dewasa ygdilakukan tindakan sot endotrakeal tube. Nilai t hitungberdasarkan uji Paired - sample T test yaitu -9,532, sedangkan nilai t tabel sebanyak doa, 063, sebagai akibatnya bisa disimpulkan Jika nilai t hitung <t tabel (-9,532< doa, 063) dan Nilai $\mathrm{P}(0,000<0,05)$ maka ada perbedaan kadar saturasi oksigen di pasien dewasa yg dilakukan tindakan sot endotrakeal tube.

Hasil rata-rata perubahan saturasi oksigen 1"-3" yaitu sebesar (0-1\%) dengan frekuensi 17 responden (68\%), sedangkan rata-rata perubahan saturasi oksigen 4"-6" sebesar (2-3\%) dengan frekuensi 22 responden $(88 \%)$, dan terakhir rata-rata perubahan saturasi oksigen 7"-10" adalah sebesar (2-3\%) dengan 16 responden (64\%), dan (4-7\%) dengan 9 responden (36\%). Menurut Afif Muhammad Nizar, dkk (2015) perubahan tersebut dapat terjadi pengaruh lapangnya airway dengan penumpukan sekresi 
sehingga menjadikan arus transportasi $\mathrm{O} 2$ dari atm ke dalam pulmonal menjadi lebih efisien. Akan tetapi masih ada faktor lain seperti penggunaan teknik open suction atau close suction, karena dari 25 responden $(100 \%)$ semuanya dilakukan tindakan suction menggunakan teknik open suction dimana tindakan open suction dilakukan dengan cara melepas sambungan endotracheal tube pada pasien dengan alat ventilator mekanik sehingga oksigen pada pasien tidak adekuat dan dapat menurunkan saturasi oksigen pasien.

Hal ini sesuai dengan hasil penelitian Marlisa, dkk (2013) dimana dari 20 responden yang diteliti 10 responden yang dilakukan tindakan suction menggunakan teknik open suction mengalami penurunan yang lebih signifikan, dibanding 10 responden yang dilakukan suction menggunakan teknik close suction. Hal ini terjadi karena open suction dilakukan dengan cara melepas sambungan endotracheal tube dengan ventilator mekanik sehingga pada saat penghisapan tidak dilakukan dengan suplai oksigen yang adekuat.

\section{KESIMPULAN}

Didapat hasil temuan perubahan kadar saturasi oksigen pada pasien dewasa yang dilakukan tindakan suction endotracheal tube di ruang ICU RSUD Ulin Banjarmasin, menggunakan rata-rata perubahan saturasi oksigen di 1 "-3" saat dilakukan tindakan sot endotrakeal tube sebanyak 0-1\%, lalu homogen-homogen perubahan saturasi oksigen 4 "-6" waktu dilakukan tindakan sot endotrakeal tube sebesar 2-tiga\%, selanjutnya homogen-homogen perubahan saturasi oksigen 7 "-10" waktu dilakukan tindakan sot endotrakeal tube sebanyak 2-3\%, dan 2 - $3 \%$ saat emnit ke-25 sehabis tindakan. Temuan ini menjadikan bahan untuk direkomendasikannya buat rekan-rekan perawat pada melakukan tindakan suction berharap sesuai baku Operasional transisi (SUAP) buat mencegah perubahan saturasi oksigen berefek membahayakan nyawa pasien.

\section{DAFTAR PUSTAKA}

Afif, Muhammad Nizar. (2017). Pengaruh Suction Terhadap Kadar Saturasi Oksigen Pada Pasien Koma Di Ruang ICU RS Dr. Moewardi Surakarta. Jurnal Keperawatan Global Vol 2, No 22017.

Elsaman, S. E. (2017). Effect of Application of Endotracheal Suction Guidelines on Cardiorespiratory Parameters of Mechanically Ventilated Patients, 6 (1), 41-48. https://doi.org/10.9790/1959$\underline{0601014148}$

Hidayat, A. Aziz. (2012). Pengantar Kebutuhan Dasar Manusia Aplikasi Konsep dan Proses Keperawatan Buku 2. Jakarta: Salemba Medika

Idjradinata, P. S., \& Eli Kosasih, C. (n.d.). Efek Suction Melalui Catheter Mouth terhadap Saturasi Oksigen Pasien Cedera Kepala .The Effect of Oxygen Supply Via Oral Catheterization in the Suction Process to the Oxygen Saturation Level in the Patient with Head Injury, 1.

Irmawan, B., \& Muflihatin, S. K. (2017). Pengaruh Tindakan Suction Terhadap Perubahan Saturasi Oksigen Perifer Pada Pasien Yang Di Rawat Diruang ICU RSUD Abdul Wahab Sjahranie Samarinda. Jurnal Ilmiah Sehat Bebaya Vol, 1(2).

Kozier, B., \& Erb, G. (2002). Kozier and Erb's Tehniques in Clinical Nursing $5^{\text {th }}$ Edition. New Jersey: Pearson Education.

Kozier \& Erb’s. (2016). Fundamentals of Nursing Concepts, Process and Practice Tenth Edition. United States of America : Julie Levin Alexader. 
Maggiore, S.M. et al,. (2013). Decreasing the Adverse Effects of Endotracheal Suctioning During Mechanical Ventilation by Changing Practice. Continuing Respiratory Care Education, Vol 58, 1588-1597.

Marlisa, dkk. (2013). Efek Suction Melalui Catheter Mouth Terhadap Saturasi Oksigen Pasien Cedera Kepala.

Martin Daniel, Barbara K Smith, et al. (2011). Inspiratory muscle strength training improves weaning outcome in failure to wean patients: a randomized trial. Critical Care.

Marton.P.G,et.all. (2013).Keperawatan Kritis Pendekatan Asuhan Holistik Volume 1 Edisi 8. Jakarta : EGC.

Nursalam. (2015). Metodologi Penelitian Ilmu Keperawatan: Pendekatan Praktis.Jakarta: Salemba Medika.

Price, S.A., Wilson, L.M (2006). Patofisiologi Konsep Klinis Proses-Proses Penyakit. Edisi 6. Volume 2. Jakarta : EGC.

Somantri, I. (2012). Asuhan Keperawatan Pada Pasien Dengan Gangguan Sistem Pernafasan. Edisi 2. Jakarta : EGC 